\title{
ASSESSMENT OF NEUROINFLAMMATORY AND NEURODEGENERATIVE ALTERATIONS IN THE BRAIN IN A MOUSE MODEL OF VISCERAL LARVA MIGRANS \\ BY
}

DINA I. ELGENDY ${ }^{1 *}$, AHMAD A. OTHMAN ${ }^{1}$, EMAN M. SAIED ${ }^{2}$, AND HAGER S. ZOGHROBAN ${ }^{1}$

Department of Medical Parasitology, Faculty of Medicine, Tanta University ${ }^{1}$ and Department of Pathology, Faculty of Medicine, Kafrelsheikh University², Egypt

$\left({ }^{*}\right.$ Correspondence: dina.elgendy@med.tanta.edu.eg

- ORCID: https://orcid.org/0000-0002-0070-6113)

Abstract

Neurotoxocariasis is a parasitic zoonosis resulting from the intrusion of the larvae of dog roundworm Toxocara canis into the central nervous system (CNS), leading to severe CNS insults, and provoking different neurological manifestations ranging from headache to convulsions and paresis. This work assessed the probable occurrence of neuroinflammatory and neuro-degenerative alterations in the brain tissues of $T$. canis infected mice and evaluated the changes in brain parasite loads over the course of infection. The total larval loads in the brain, histopathological, immunohistochemical (MMP-3 \& MMP-9) examination as well as determination of NF$\mathrm{\kappa B}$ and Tau protein levels in the brain tissues were done. In spite of the absence of inflammatory cell infiltration around larvae in brain tissues of mice, expressions of all the investigated markers of neuroinflammation and neurodegeneration showed an ascending pattern throughout the course of the infection and were directly proportional to the increase in the brain larval loads.

Keywords: Neurotoxocariasis, Neuroinflammation, Neurodegeneration, MMP-3, MMP-9, NF$\kappa \mathrm{B}$, Tau protein.

\section{Introduction}

The chief causative agent of visceral larva migrans is the common nematode parasite of dogs: Toxocara canis (T. canis). It affects a large scale of animal hosts as well as humuns (Castillo et al, 2000). Studies on seroprevalance rates of human toxocariasis reported that it is one of the most prevalent helminthes worldwide (Abdi et al, 2014; Ebrahimifard et al, 2015; Wang et al, 2020). Its prevalence rates ranged from $2-5 \%$ in urban areas to $35-42 \%$ in rural areas (Magnaval et al, 2001; Rubinsky-Elefant et al, 2010; Shokouhi et al, 2018). Human infection took place by ingestion of the embryonated $T$. canis eggs containing third-stage larvae in contaminated soil, foodstuffs or water and by ingestion of raw or improperly cooked tissues of various paratenic hosts containing infective viable larvae (Strube et al, 2013). Upon liberation of the infective larvae in the gastrointestinal tract, they penetrated the intestinal mucosa and were carried by the circulation to diverse parts of the body. At about the 7th day post infection (P.I.), they entered the CNS (Abo-Shehada and Herbert, 1984). The larvae produced a variety of injurious substances including enzymes, excretory substances, and cuticular structures, which stimulated remarkable local immune responses that resulted in destruction of the affected tissues (Xinou et al, 2003).

Invasion of the CNS by $T$. canis larvae results in the neurotoxocariasis (Strube et al, 2013). In humans, this condition may be asymptomatic or it may lead to severe CNS insults such as eosinophilic meningitis, encephalitis, myelitis and cerebral vasculitis (Dousset et al, 2003; Sánchez et al, 2018; Morsy, 2020). Patients may suffer from different neurological manifestations including principally headaches, convulsions, paresis and behavioral disorders (Fan et al, 2015).

Furthermore, a correlation between Toxocara infection and cognitive decline, learning disabilities and memory disorders had been evidenced (Scheid et al, 2008; Walsh and Haseeb, 2012; Erickson et al, 2015).

Neurotoxocariasis is still considered as a poorly understood disorder. Moreover, the 
underlying mechanisms by which $T$. canis larvae could invade and induce damage in the brain tissues of the affected host remain particularly deficient (Waindok and Strube, 2019). Besides, data were accumulating in the literature about probable link between neurotoxocariasis and a number of neurodegenerative diseases such as idiopathic Parkinson's disease, Alzheimer's disease and depression (Fan et al, 2015; Janecek et al, 2017).

The present study aimed to explore the potential development of neuroinflammatory and neurodegenerative alterations in the brain tissues of $T$. canis infected mice and to assess the correlation between these changes and the brain parasite loads over the course of infection.

\section{Material and Methods}

Parasite: T. canis eggs, obtained by flotation technique from stools of puppies, were cultured in $0.1 \mathrm{~N}_{2} \mathrm{SO}_{4}$ for embryonation and storage. Infections were done using eggs from culture not more than two months old (Kayes and Oaks, 1976). Prior to infection of mice, the eggs were washed for three times in physiological saline to eliminate the physiological saline/ $\mathrm{H}_{2} \mathrm{SO}_{4}$ solution. Eggs were then re-suspended in distilled water and their concentration was adjusted to be 1000 embryonated eggs per $0.25 \mathrm{ml} .1000$ embryonated eggs were administered to each mouse in infected group by intragastric inoculation (Chou et al, 2017).

Animals and experimental design: Laboratory bred male Swiss albino mice (6-8weeks old and 20-25g in weight) were used in this work. Mice were housed and fed according to the national and institutional guidelines for the care and use of laboratory animals. A total of 45 mice were divided into 2 groups: G1:15 mice, non-infected mice as a negative control group; and G2: 30 mice, T. canisinfected mice. Collection of samples was done at the end of weeks $3,7, \& 15$ P.I. Ten mice from the infected group and 5 mice from the negative control group were sacrificed at each time point P.I. and divided as follows: Five mice from infected group for brain larval counting, and 5 mice from every one of the 2 groups, brains were divided into two parts one for histopathological and immunohistochemical examinations and the second for biochemical assays.

Total larval loads in the brain: The infected animals were sacrificed, and the whole brain from each mouse was retrieved in a clean Petri dish. The two halves of the cerebrum and the cerebellum were detached and each half was squashed between two microscopic slides followed by its examination under the low power of a light microscope to estimate total brain larval counts (Kayes and Oaks, 1976).

Histopathological study: Brain tissue samples from the studied groups were fixed by immersion in $10 \%$ formalin at once, and then routine histological processing was done. They were embedded in paraffin followed by microtomy and staining with hematoxylin \& eosin to observe histopathological changes in the brain of the infected mice group at different studied time points P.I.

Immunohistochemical staining for determination of matrix metalloproteinases (MMP3 \& MMP-9) expression was done according to the manufacturer's protocol using the Ultra-Vision Detection Kit (TP-015-HD, Lab Vision, USA), rabbit polyclonal anti-MMP3 antibody (Cat. No. PA5-27936, Lab Vision, USA) in 1:100 dilution and rabbit polyclonal anti-MMP-9 (Cat. No. ab38898: abcam, USA).

Evaluation of MMP-3 \& MMP-9 was by immunohistochemical staining (Hou et al, 2012). Positive immunostaining was distinguished as brown granular cytoplasmic staining. The immunostaining of both antibodies was scored as follows: percentage of each antibody stained area in five rand-om images per mouse were determined \& analyzed by Image $\mathbf{J}$ software (Java image processing program inspired by $\mathrm{NIH}$ ) and mean was calculated for each group.

Biochemical study: determination of NF$\kappa \mathrm{B}$ (nuclear factor kappa-light-chain-enhan- 
cer of activated B cells) and Tau protein (a microtubule-associated protein, mainly expressed in the neuronal cells) levels in brain tissue homogenates was done using ELISA kits for quantitative detection of mouse NF$\kappa \mathrm{B}$ (Catalog no. MBS2023542: MyBio-Source, USA) \& Tau protein (Catalog no. LSF6386: Life-Span Bioscience, USA) following the manufacturer's protocol.

Statistical analysis: Data were presented as $\mathrm{M} \pm \mathrm{SD}$. Kruskal-Wallis test was used to compare all the experimental groups followed by post-hoc test to detect significance between groups. Differences were considered significant when $(\mathrm{P}<0.05)$. Analyses were done using Statistical Program of Social Sciences (SPSS Inc., Chicago, Illinois, USA), software for windows, version (20).

Ethics statement: The study protocol was approved and conducted according to the guidelines of the Laboratory Animal Centre for Research Ethics Committee, Faculty of Medicine, Tanta University (Approval code: $33557 / 12 / 19)$.

\section{Results}

Brain larval loads: T. canis larval counts in the brain tissues of the infected mice at different time points P.I. (Tab. 1). Larval counts showed an ascending pattern, denoting progressive accumulation of $T$. canis larvae in the brain. Almost all larvae showed signs of viability on close observation. In sum, there was a significant increment of larval counts in brain as the infection proceeded.

Histopathological examination of brain sections of infected mice revealed the $T$. $c a$ nis larvae that were not surrounded by any inflammatory cell infiltration. Similar observations were detected in all examined brain sections of the infected group at all studied time points P.I. (Fig. 1).

Immunohistochemical assessment of the MMP-3 \& MMP-9 reactivity: The expressions of MMP-3 \& MMP-9 (Fig. 2 \&3) in brain tissues of infected mice were significantly higher than expressions in negative control group. Expressions of both markers increased significantly with increasing infection duration. They were detected as early as the $3^{\text {rd }}$ week P.I. and showed an ascending pattern throughout the course of infection (Tab. 2).

Biochemical results: A significant increase in NF- $\kappa \mathrm{B}$ levels in brain tissue homogenates was detected in T. canis infected mice compared to the negative control group. Likewise, Tau protein levels were significantly upregulated in the infected group compared to the negative control group. Levels of both markers showed a significant elevation over the course of the infection reaching the highest levels at the $15^{\text {th }}$ week P.I. (Tab. 3).

Table 1: Larval loads in brain of infected mice at different time points P.I. $(n=5)$

\begin{tabular}{|c|c|c|c|}
\hline Group & 3 weeks P.I. & 7 weeks P.I. & 15 weeks P.I. \\
\hline G2 & $74.50 \pm 5.15$ & $106.50 \pm 7.52$ & $161.70 \pm 5.46$ \\
\hline \multicolumn{4}{|c|}{$P 1<0.001^{*}, P 2<0.001^{*}, P 3<0.001^{*}$} \\
\hline
\end{tabular}

* significante $P<0.05$; P1 compared between larval count at $3 \& 7$ weeks P.I., P2 compared between larval count at $3 \& 15$ weeks P.I., P3 compared between larval count at $7 \& 15$ weeks P.I.

Table 2: Comparison of MMP-3 \& MMP-9 expressions in brain sections of all studied groups $(\mathrm{n}=5)$

\begin{tabular}{|c|c|c|}
\hline \multirow{2}{*}{ Groups } & Percentage of MMP-3 stained area & Percentage of MMP-9 stained area \\
\cline { 2 - 3 } & Mean \pm SD & Mean \pm SD \\
\hline G1 & $2.96 \pm 0.25$ & $3.06 \pm 0.24$ \\
\hline G2 (3 weeks P.I.) & $18.02 \pm 0.28$ & $22.35 \pm 0.57$ \\
\hline G2 (7 weeks P.I.) & $45.12 \pm 2.03$ & $50.45 \pm 0.55$ \\
\hline G2 (15 weeks P.I.) & $81.71 \pm 1.44$ & $83.52 \pm 0.71$ \\
\hline$P$ value (K W test) & $<0.001^{*}$ & $<0.001^{*}$ \\
\hline$P$ value (multiple & $P 1<0.001^{*}, P 2<0.001^{*}, P 3<0.001^{*}, P 4<$ & $P 1<0.001^{*}, P 2<0.001^{*}, P 3<0.001^{*}$ \\
comparison) & $0.001^{*}, P 5<0.001^{*}, P 6<0.001^{*}$ & $P 4<0.001^{*}, P 5<0.001^{*}, P 6<0.001^{*}$ \\
\hline
\end{tabular}

* Significant $P<0.05 P 1$ compared between G1 \& G2 (3 weeks P.I.), $P 2$ compared between G1 \& G2 (7 weeks P.I.), $P 3$ compared between G1 \& G2 (15 weeks P.I.), P4 compared between G2 (3 weeks P.I.) \& G2 (7 weeks P.I.), P5 compared between G2 (3 weeks P.I.) \& G2 (15 weeks P.I.), P6 compared between G2 (7 weeks P.I.) \& G2 (15 weeks P.I.) 
Table 3: Comparison of NF- $\mathrm{BB} \&$ Tau protein levels in brain tissue homogenates of all groups $(\mathrm{n}=5)$

\begin{tabular}{|c|c|c|}
\hline Groups & NF- $\mathrm{kB} \mathrm{ng} / \mathrm{ml}$ & Tau protein ng/mL \\
\hline G1 & $0.386 \pm 0.019$ & $0.69 \pm 0.13$ \\
\hline G2 (3 weeks P.I.) & $3.798 \pm 0.406$ & $2.15 \pm 0.26$ \\
\hline G2 (7 weeks P.I.) & $7.031 \pm 0.275$ & $6.09 \pm 0.17$ \\
\hline G2 (15 weeks P.I.) & $10.987 \pm 0.264$ & $9.22 \pm 0.51$ \\
\hline F test & 109.354 & 85.214 \\
\hline$P$ value (multiple & $P 1<0.001^{*}, P 2<0.001^{*}, P 3<0.001^{*}$, & $P 1<0.001^{*}, P 2<0.001^{*}, P 3<0.001^{*}$, \\
comparison) & $P 4<0.001^{*}, P 5<0.001^{*}, P 6<0.001^{*}$ & $P 4<0.001^{*}, P 5<0.001^{*}, P 6<0.001^{*}$ \\
\hline
\end{tabular}

\section{Discussion}

Some parasites possess a predilection to gain access to the CNS (Bencurova et al, 2011). T. canis larva is one of these parasites that invade the CNS, provoking a spectrum of manifestations in the affected humans and animals. Up till now, the mechanisms of invasion and injury of the brain parenchyma by $T$. canis larvae were not fully elucidated (Waindok and Strube, 2019). In this context, certain molecules may facilitate the larval movement and migration as well as the induction of pathological changes in the CNS. That's why, this study investigated the effect of $T$. canis infection on the expression of different markers including MMP-3, MMP$9, \mathrm{NF}-\kappa \mathrm{B}$ and Tau protein which are highly involved in the pathogenesis of traumatic brain injury, neuroinflammation and neurodegenerative disorders (Liao et al, 2008; Sabbagh et al, 2013), suggesting that they may have a role in the pathogenesis of neurotoxocariasis.

In the present study, the brain larval loads showed an ascending pattern in the accumulation of larvae in the infected animal's brain tissues over the infection course. These results agreed with Lai et al. (2005) and Chou et al. (2017) who reported a steady increment of larval loads in the brain with time. This progressive accumulation of the larvae in brain could be due to the favorable environment for the larvae survive as it is an immune-privileged site where the larvae become protected from the host immune response (Holland and Hamilton, 2013).

The absence of inflammatory cell infiltration in the brains of $T$. canis infected mice that had been detected in the present work is confirmative to the findings of Liao et al. (2008), Eid et al. (2015) and Chou et al.
(2017) on T. canis-infected outbred mouse strains. But, Springer et al. (2019) detected perivascular cuffs with eosinophils and neutrophils in $\mathrm{C} 57 \mathrm{Bl} / 6$ mice infected with $T$. canis. This could be explained by the difference between the immune response of inbred and outbred mice to $T$. canis infection.

This work showed that the infection with $T$. canis resulted in a significant upregulation of MMP-3 expression in the brain tis-sues of the infected mice. In addition, its expression increased progressively over the course of the infection and it was directly proportional to the larval counts in the brain tissues. To date and to the best of our knowledge, no data are available in the literature on the expression of MMP-3 in the brains of T. canisinfected mice. Interestingly, it was found that its expression increased in response to other parasitic infections such as Plasmodium falciparum infection (D'Alessandro et al, 2013). MMP-3 is able to break down numerous extracellular matrix proteins, trigger growth factors and degrade cell adhesion particles, chemokines, cytokines and a mixture of receptors. Also, it activates MMP-9 promoter (Ogata et al, 1992; Arza et al, 2000; McCawley and Matrisian, 2001). It could disrupt the blood-brain barrier, promote demyelination and apoptosis, and induce additional inflammatory responses.

Therefore, the over-expression of MMP-3 supports neuroinflammation and apoptosis and leads to exacerbation of numerous neurodegenerative diseases (Kim et al, 2010; Cauwe and Opdenakker, 2010).

In the current work, the expression of MMP-9 in the brain tissues of the infected animals significantly increased in comparison to the negative control animals and it 
was proportional to the larval recovery rate in the brain tissues. These results were similar to those of Lai et al. (2005) who reported that activity of MMP-9 increased in the lungs, liver, muscles, and brain tissues during T. canis larval migration. Besides, Shyu et al. (2019) demonstrated that MMP-9 had a major job in granuloma formation during the progression of ocular toxocariasis via reinforcement of inflammatory cell infiltration and degradation of extracellular matrix proteins.

MMP-9 owns a noteworthy role in the pathogenesis of neuroinflammatory diseases (Khuth et al, 2001; Yong et al, 2001; Rosenberg, 2002). A consistent increment in its levels in the cerebrospinal fluid is considered as an indicator of neuroinflammation over course of various diseases influencing the CNS, for example, multiple sclerosis as well as bacterial and viral meningitis (Giraudon et al, 1998; Leppert et al, 1998; Sporer et al, 1998; Matsuura et al, 2000; Yushchenko et al, 2000). Also, a similar perception was recognized on investigating the cerebrospinal fluid of animals affected with infectious or inflammatory conditions of the CNS (Gijbels et al, 1993; Azeh et al, 1998; Paul et al, 1998). Besides, the critical role of MMP-9 in synaptic plasticity, learning, and memory were brought forward by many authors (Szklarczyk et al, 2002; Meighan et al, 2006; Nagy et al, 2006; Okulski et al, 2007; Tian et al, 2007).

Indeed, the excessive expression of the MMPs, especially MMP-3 \& MMP-9, was implicated in several conditions of acute brain insult including hemorrhagic, ischemic and traumatic lesions (Kim et al, 2010; Heo et al, 1999; Wang et al, 2000). Moreover, a strong evidence about their contribution in the pathology of neurodegenerative diseases such as multiple sclerosis and Alzheimer's disease is well established (Hartung and Kieseier, 2000; Lorenzo et al, 2003). Additionally, in the last decade, several studies supported the role of MMPs in the pathogenesis of some neurological disorders caused by the parasitic infections either protozoal (Clark et al, 2010; Thibeaux et al, 2014; Jacintho et al, 2018) or helminthic (Verma et al, 2011; Wei et al, 2011; Bruschi et al, 2014).

$\mathrm{NF}-\kappa \mathrm{B}$ is a common constituent in nearly all categories of cells in the brain (O'Neill and Kaltschmidt, 1997). Its activation and increased expression within astrocytes caused significantly amplify neuronal degeneration (Mattson and Camandola, 2001; Johnstone et al, 2013). Moreover, increased expression of NF- $\mathrm{KB}$ was reported in diverse acute and chronic neurodegenerative disorders such as ischemic brain injury (Zhou et $a l$, 2018), Traumatic brain injury (Chen et al, 2017), Alzheimer's disease (Chen et al, 2005) and Parkinson's disease (Mogi et al, 2007). The present work showed that there was upregulation in the levels of NF- $\kappa \mathrm{B}$ in the brains of $T$. canis infected mice over the course of infection. These results suggest a role of NF- $\kappa \mathrm{B}$ in the pathogenesis of neurotoxocariasis. Previous studies on the NF- $\kappa B$ signaling pathway showed that there is a link between NF- $\mathrm{KB}$ activation and the induction of MMP-9 gene expression. This could be a direct effect by binding to the NF- $\mathrm{KB}$ element in the MMP-9 promoter or an indirect effect by triggering other transcription factors that have the capacity to stimulate MMP-9 gene expression (Brown et al, 1995; Fujioka et al, 2004; Gordon et al, 2009).

The main protective barrier against the passage of various injurious elements including pathogens into the CNS is the bloodbrain barrier (BBB). The mechanisms by which the neurotropic parasites manipulate the BBB differ according to the extracellular or intracellular nature of these parasites. In contrast to intracellular parasites, the mechanisms of disruption or interaction with the BBB were largely unknown for extracellular parasites including $T$. canis (Masocha and Kristensson, 2012). However, metalloproteases were found to be crucial for crossing the $\mathrm{BBB}$ during the infection by the extracellular parasite Balamuthia mandarillaris 
(Matin et al, 2006). Also, other parasites reaching the CNS, various cytokines, chemokines, and adhesion molecules- all with close interaction with various MMPs were implicated in the interaction with BBB (Masocha and Kristensson, 2012). So, this study may help explain the cross-talk between Toxocara larvae and the BBB. This context suggested a mechanism for the process of CNS invasion and migration by $T$. canis larvae. It assumed that activation of MMP-9 \& NF- $\kappa B$ results in an increase in $\mathrm{BBB}$ permeability and disruption of tight junction proteins, facilitating the pa-ssage and movement of the larvae through the tissues. The findings of Chiu and Lai (2013) who reported that BBB dysfunction in angiostrongyloidosis was mediated by MMP-9 via the NF- $\mathrm{KB} / \mathrm{MMP}-9$ signaling pathway are support for these explanations. However, whether T. canis larvae exclusively provokes the expression of host metalloproteases or produces its proper metalloproteases needs further research.

Tau protein is an essential physical component of neurons that has an important role in assembly and stabilization of microtubules. Alterations in the distribution of tau protein in neurons and its accretion in the form of insoluble fibrillary deposits are highly consistent with death of neuronal cell. So, it was considered as an indicator of neurodegeneration (Williams, 2006; Wang et al, 2012). The expression of tau protein was significantly elevated with time in brain tissues of $T$. canis infected mice compared to negative controls. This agreed with Liao et al. (2008) and gave evidence on the occurrence of progressive neurodegenerative changes in brain because of $T$. canis infection.

\section{Conclusion}

The results reported that $T$. canis infection induced the production of MMP-9 and its activator MMP-3 as well as NF-B and Tau protein in the brain tissues of infected mice. This could provide insights on the contribution of these molecules in the pathogenesis of neurotoxocariasis through the processes of larval invasion and migration within the
CNS as well as the induction of inflammation and neurodegeneration. The molecules can also be useful as markers of inflammation during neurotoxocariasis. Also, correlation could be between NF- $\mathrm{KB} / \mathrm{MMP}-9$ signaling pathway and ability of $T$. canis larvae to invade and migrate within CNS. Thus, MMPs or their inhibitors have potential targets for dealing with diagnosis, treatment, and control of neurotoxocariasis and possibly of other CNS disorders as well.

Conflict of interest: Authors declared that they neither have interest nor received fund.

\section{References}

Abdi, J, Farhadi, M, Aghace, S, Sayehmiri, K, 2014: Parasitic contamination of raw vegetables in Iran: A systematic review and meta-analysis. J. Med. Sci. 14, 3:137-42.

Abo-Shehada, MN, Herbert, IV, 1984: The migration of larval Toxocara canis in mice IIPost-intestinal migration in primary. Vet. Parasitol. 171:75-83.

Arza, B, Hoylaerts, MF, Félez, J, Collen, D, Lijnen, HR, 2000: Prostromelysin1 pro MMP3 stimulates plasminogen activation by tissue type plasminogen activator. Eur. J. Biochem. 26721: 6378-84.

Azeh, I, Mäder, M, Smirnov, A, Beuche, W, Nau, R, et al, 1998: Experimental pneumococcal meningitis in rabbits: the increase of matrix metalloproteinase-9 in cerebrospinal fluid correlates with leucocyte invasion. Neurosci. Lett. 2563:127-30.

Bencurova, E, Mlynarcik, P, Bhide, M, 2011: An insight into the ligand-receptor interactions involved in the translocation of pathogens across blood-brain barrier. FEMS. Immunol. Med. Microbiol. 633:297-318.

Brown, RT, Ades, IZ, Nordan, RP, 1995: An acute phase response factor/NF-kappa B site downstream of the junB gene that mediates responsiveness to interleukin- 6 in a murine plasmacytoma. J. Biol. Chem. 270, 52: 31129-35. Bruschi, F, Bianchi, C, Fornaro, M, Naccarato, G, Menicagli, M, et al, 2014: Matrix metallo -proteinase MMP-2 \& MMP-9 as inflammation markers of Trichinella spiralis and Trichinella pseudospiralis infections in mice. Parasite Immunol. 3610:540-9.

Castillo, D, Paredes, C, Zanartu, C, Castillo, G, Mercado, R, et al, 2000: Environmental con- 
tamination with Toxocara sp. eggs in public squares and parks from Santiago, Chile, 1999. Bol. Chil. Parasitol. 55, 3/4:86-91.

Cauwe, B, Opdenakker, G, 2010: Intracellular substrate cleavage: A novel dimension in the biochemistry, biology and pathology of matrix metalloproteinases. Crit. Rev. Biochem. Mol. Biol. 455:351-423.

Chen, J, Zhou, Y, Mueller-Steiner, S, Chen, L F, Kwon, H, et al, 2005: SIRT1 protects against microglia-dependent amyloid-beta toxicity through inhibiting NF-kappaB signaling. J. Biol. Chem. 280:40364-74.

Chen, X, Wu, S, Chen, C, Xie, B, Fang, Z, et al, 2017: Omega-3 polyunsaturated fatty acid supplementation attenuates microglial-induced inflammation by inhibiting the HMGB1/TLR4/ NF- $\kappa \mathrm{B}$ pathway following experiment-al traumatic brain injury. J. Neuroinflamm-at. 14, 1:1436.

Chiu, PS, Lai, SC, 2013: Matrix metalloproteinase-9 leads to claudin-5 degradation via the $\mathrm{NF}-\kappa \mathrm{B}$ pathway in BALB/c mice with eosinophilic meningoencephalitis caused by Aniostrongylus cantonensis. PLoS. One 8, 3: e53370.

Chou, CM, Lee, YL, Liao, CW, Huang, YC, Fan, CK, 2017: Enhanced expressions of neurodegeneration-associated factors, UPS impairment, and excess $A \beta$ accumulation in the hippocampus of mice with persistent cerebral toxocariasis. Parasit. Vect. 101:620-6.

Clark, RT, Nance, JP, Noor, S, Wilson, EH, 2010: T-cell production of matrix metalloproteinases and inhibition of parasite clearance by TIMP-1 during chronic Toxoplasma infection in brain. ASN Neuro. 31:AN20100027.

D'Alessandro, S, Basilico, N, Prato, M, 2013: Effects of Plasmodium falciparum-infected erythrocytes on matrix metalloproteinase-9 regulation in human microvascular endothelial cells. Asian Pac. J. Trop. Med. 63: 195-9.

Dousset, V, Sibon, I, Menegon, P, 2003: Case no 6 cerebral vasculitis due to Toxocara canis or T. catis origin. J. Radiol. 841:89-91.

Ebrahimifard, SF, Fakhar, M, Sharif, M, Nasrollahpoor Shirvani, SD, 2015: Seroprevalence of Toxocara infection among adult individua1s with eosinophilia in Babol, 2013. J. Mazandaran Univ. Med. Sci. 25, 121:355-62.

Eid, MM, El-Kowrany, SI, Othman, AA, EI Gendy, DI, Saied, EM, 2015: Immunopathological changes in the brain of immunosuppressed mice experimentally infected with Toxocara $\mathrm{ca}$ nis. Korean J. Parasitol. 53:51-8.

Erickson, LD, Gale, SD, Berrett, A, Brown, B L, Hedges, DW, 2015: Association between toxocariasis and cognitive function in young to the middle-aged adults. Folia Parasitol. (Praha) 62: 48-51.

Fan, CK, Holland, CV, Loxton, K, Barghouth, U, 2015: Cerebral toxocariasis: Silent progression to neurodegenerative disorders? Clin. Microbiol. Rev. 283:663-86.

Fujioka, S, Niu, J, Schmidt, C, Sclabas, GM, Peng, B, et al, 2004: NF-kappaB and AP-1 connection: Mechanism of NF-kappaB-dependent regulation of AP-1 activity. Mol. Cell. Biol. 24, 17:7806-19.

Gijbels, K, Proost, P, Masure, S, Carton, H, Billiau, A, et al, 1993: Gelatinase B is present in the cerebrospinal fluid during experimental autoimmune encephalomyelitis and cleaves myelin basic protein. J. Neurosci. Res. 364:432-40.

Giraudon, P, Vernant, JC, Confavreux, C, Belin, MF, Desgranges, C, 1998: Matrix metalloproteinase 9 gelatinase B in cerebrospinal fluid of HTLV-1 infected patients with tropical spastic paraparesis. Neurology 506:1920-6

Gordon, GM, Ledee, DR, Feuer, WJ, Fini, M E, 2009: Cytokines and signaling pathways regulating matrix metalloproteinase-9 (MMP-9) expression in corneal epithelial cells. J. Cell. Physiol. 221, 2:402-11.

Hartung, HP, Kieseier, BC, 2000: The role of matrix metalloproteinases in autoimmune damage to the central and peripheral nervous system. J. Neuroimmunol. 1072:140-7.

Heo, JH, Lucero, J, Abumiya, T, Koziol, JA, Copeland, BR, et al, 1999: Matrix metalloproteinases increase very early during experimental focal cerebral ischemia. J. Cereb. Blood Flow Metab. 196:624-33.

Holland, CV, Hamilton, CM, 2013: The significance of cerebral toxocariasis: A model system for exploring the link between brain involvement, behavior and the immune response. J. Exp.

Biol. 2161:78-83.

Hou, X, Yu, F, Man, S, Huang, D, Zhang, Y, et al, 2012: Negative regulation of Schistosoma japonicum egg-induced liver fibrosis by natural killer cells. PLoS Negl. Trop. Dis. 61: e1456. Jacintho, APP, Melo, GD, Machado, GF, Bertolo, PHL, Moreira, PRR, et al, 2018: Expression of matrix metalloproteinase-2 and metallo- 
proteinase-9 in the skin of dogs with visceral leishmaniasis. Parasitol. Res. 1176:1819-27.

Janecek, E, Wando, P, Bankstahl, M, Strube, C, 2017: Abnormal neurobehavioral and impaired memory function as a consequence of Toxocara canis-and Toxocara cati-induced neurotoxocarosis. PLoS. Negl. Trop. Dis. 115: e0005594.

Johnstone, JT, Morton, PD, Jayakumar, AR, Bracchi-Ricard, V, Runko, E, et al, 2013: Reduced extracellular zinc levels facilitate glutamate-mediated oligodendrocyte death after trauma. J. Neurosci. Res. 91:828-37.

Kayes, SG, Oaks, JA, 1976: Effect of inoculum size and length of infection on the distribution of Toxocara canis larvae in the mouse. Am. J. Trop. Med. Hyg. 254:573-80.

Khuth, ST, Akaoka, H, Pagenstecher, A, Verlaeten, O, Belin, MF, et al, 2001: Morbilli virus infection of the mouse central nervous system induces region-specific upregulation of MMPs \& TIMPs correlated to inflammatory cytokine expression. J. Virol. 7517: 8268-82.

Kim, EM, Shin, EJ, Choi, JH, Son, HJ, Park, IS, et al, 2010: Matrix metalloproteinase-3 is increased and participates in neuronal apoptotic signaling downstream of caspase-12 during endoplasmic reticulum stress. J. Biol. Chem. 28522: 16444-52.

Lai, SC, Chen, KM, Chen, HC, Lee, HH, 2005: Induction of matrix metalloproteinase-9 in mice during Toxocara canis larvae migration. Parasitol. Res. 953:193-200.

Leppert, D, Ford, J, Stabler, G, Grygar, C, Lienert, C, et al, 1998: Matrix metalloproteinase-9 gelatinase B is selectively elevated in CSF during relapses and stable phases of multiple sclerosis. Brain J. Neurol. 121, 12: 2327-34.

Liao, CW, Fan, CK, Kao, TC, Ji, DD, Su, KE, et al, 2008: Brain injury-associated biomarkers of TGF-beta1, S100B, GFAP, NF-L, tTG, Abeta $\mathrm{PP}$, and tau were concomitantly enhanced and the UPS was impaired during acute brain injury caused by Toxocara canis in mice. BMC Infect. Dis. 8:84-8.

Lorenzo, S, Albers, DS, Relkin, N, Ngyuen, T, Hilgenberg, SL, et al, 2003: Increased plasma levels of matrix metalloproteinase-9 in patients with Alzheimer's disease. Neurochem. Int. 43, 3: 191-6.

Lull, ME, Block, ML, 2010: Microglial activation and chronic neurodegeneration. Neurotherapeutics 74:354-65.

Magnaval, JF, Glickman, LT, Dorchies, P,
Morassin, B, 2001: Highlights of human toxocariasis. Korean J. Parasitol. 39, 1:1-11.

Masocha, W, Kristensson, K, 2012: Passage of parasites across the blood-brain barrier. Virulence 3, 2:202-12.

Matin, A, Stins, M, Kim, KS, Khan, NA, 2006: Balamuthia mandrillaris exhibits metalloprotease activities. FEMS Immunol. Med. Microbiol. 47: 83-91.

Mattson, MP, Camandola, S, 2001: NF- $\kappa B$ in neuronal plasticity and neurodegenerative disorders. J. Clin. Invest. 107, 3:247-54.

McCawley, LJ, Matrisian, LM, 2001: Matrix metalloproteinases: they're not just for matrix anymore! Curr. Opin. Cell Biol. 135:534-40.

Meighan, SE, Meighan, PC, Choudhury, P, Davis, CJ, Olson, ML, et al, 2006: Effects of extracellular matrix degrading proteases matrix metalloproteinases $3 \& 9$ on spatial learning and synaptic plasticity. J. Neurochem. 965:1227-41.

Mogi, M, Kondo, T, Mizuno, Y, Nagatsu, T, 2007: p53 protein, interferon $-\gamma$, and NF- $\kappa B$ levels are elevated in the parkinsonian brain. Neurosci. Lett. 414, 1:94-7.

Morsy, TA, 2020: Toxocariasis: Visceral and ocular larva migrans. J. Egypt. Soc. Parasitol. $50,1: 41-8$

Nagy, V, Bozdagi, O, Matynia, A, Balcerzyk, M, Okulski, P, et al, 2006: Matrix metalloproteinase-9 is required for hippocampal late-phase long-term potentiation and memory. J. Neurosci. 267:1923-34.

O'Neill, LA, Kaltschmidt, C, 1997: NF-kappa B: a crucial transcription factor for glial and neuronal cell function. Trends Neurosci. 20:252-8.

Ogata, Y, Enghild, JJ, Nagase, H, 1992: Matrix metalloproteinase 3 stromelysin activates the precursor for the human matrix metalloproteinase 9. J. Biol. Chem. 2676:3581-4.

Okulski, P, Jay, T, Jaworski, J, Duniec, K, Dzwonek, J, et al, 2007: TIMP-1 abolishes MMP-9-dependent long-lasting long-term potentiation in the prefrontal cortex. Biol. Psychiatry. 624:359-62.

Paul, R, Lorenzl, S, Koedel, U, Sporer, B, Vog el, U, et al, 1998: Matrix metalloproteinases contribute to blood-brain barrier disruption during bacterial meningitis. Ann. Neurol. 444:592-600. Rosenberg, GA, 2002: Matrix metalloproteinases in neuroinflammation. Glia 393:279-91.

Rubinsky-Elefant, G, Hirata, CE, Yamamoto, JH, Ferreira, MU, 2010: Human toxocariasis: Diagnosis, worldwide seroprevalences and cl- 
inical expression of the systemic and ocular forms. Ann. Trop. Med. Parasitol. 1041:3-23.

Sabbagh, JJ, Kinney, JW, Cummings, JL, 2013: Alzheimer's disease biomarkers: Correspondence between human studies and animal models. Neurobiol. Dis. 56:116-30.

Sánchez, SS, García, HH, Nicoletti, A, 2018: Clinical and magnetic resonance imaging findings of neurotoxocariasis. Front. Neurol. 9:53-6.

Scheid, R, Jentzsch, RT, Schroeter, M, 2008: Cognitive dysfunction, urinary retention, and a lesion in the thalamus-beware of possible toxocariasis of the central nervous system. Clin. Neurol. Neurosurg. 110, 10:1054-7.

Shokouhi, S, Abdi, J, 2018: Seroprevalence of Toxocara in children from urban and rural areas of Ilam Province, West Iran. Osong. Publ. Hlth. Res. Perspect. 9, 3:101-104.

Shyu, LY, Chen, KM, Lai, SC, 2019: Matrix metalloproteinase-2 and matrix metalloproteinase-9 in mice with ocular toxocariasis. Parasitol. Res. 1182:483-91.

Sporer, B, Paul, R, Koedel, U, Grimm, R, Wick, M, et al, 1998: Presence of matrix metalloproteinase-9 activity in the cerebrospinal fluid of human immunodeficiency virus-infected patients. J. Infect. Dis. 1783:854-7.

Springer, A, Heuer, L, Janecek-Erfurth, E, Beineke, A, Strube, C, 2019: Histopathological characterization of Toxocara canis-and T. catiinduced neurotoxocarosis in the mouse model. Parasitol. Res. 118, 9:2591-600.

Strube, C, Heuer, L, Janecek, E, 2013: Toxocara spp. infections in paratenic hosts. Vet. Parasitol. 1934:375-89.

Szklarczyk, A, Lapinska, J, Rylski, M, Mc-Kay, RD, Kaczmarek, L, 2002: Matrix metallopro-teinase-9 undergoes expression and activation during dendritic remodeling in adult hippocampus. J. Neurosci. 223:920-30.

Thibeaux, R, Avé, P, Bernier, M, Morcelet, M, Frileux, P, et al, 2014: The parasite Entamoeba histolytica exploits the activities of human matrix metalloproteinases to invade colonic tissue. Nat. Commun.5:5142-5.

Tian, L, Stefandakis, M, Ning, L, Van Lint, P, Nyman-Hutten, H, et al, 2007: Activation of NMDA receptors promote dendritic spine devel- opment through MMP-mediated ICAM-5 cleavage. J. Cell. Biol. 1784:687-700.

Verma, A, Prasad, KN, Nyati, KK, Singh, SK, Singh, AK, et al, 2011: Association of MMP-2 and MMP-9 with clinical outcome of neurocysticercosis. Parasitol. 13811:1423-8.

Waindok, P, Strube, C, 2019: Neuroinvasion of Toxocara canis-and T. cati-larvae mediates dynamic changes in brain cytokine and chemokine profile. J. Neuroinflamm. 161:147-9.

Walsh, MG, Haseeb, MA, 2012: Reduced cognitive function in children with toxocariasis in a nationally representative sample of the United States. Int. J. Parasitol. 4213, 14:1159-63.

Wang, JZ, Xia, YY, Grundke, I, Iqbal, K, 2012: Abnormal hyperphosphorylation of tau: Sites, regulation, and molecular mechanism of neurofibrillary degeneration. J. Alzheimers Dis. 33, 11:123-39.

Wang, S, Li, H, Yao, Z, Li, P, Wang, D, et al, 2020: Toxocara infection: seroprevalence and associated risk factors among primary school children in central China. Parasite 27: 30-5.

Wang, X, Jung, J, Asahi, M, Chwang, W, Russo, L, et al, 2000: Effects of matrix metalloproteinase-9 gene knockout on morphological and motor outcomes after traumatic brain injury. J. Neurosci. 2018:7037-42.

Wei, PC, Tsai, CH, Chiu, PS, Lai, SC, 2011: Matrix metalloproteinase-12 leads to elastin degradation in BALB/c mice with eosinophilic meningitis caused by Angiostrongylus cantonensis. Int. J. Parasitol. 4111:1175-83.

Williams, DR, 2006: Tauopathies: Classification and clinical update on neurodegenerative diseases associated with microtubule associated protein tau. Int. Med. J. 36:652-60.

Xinou, E, Lefkopoulos, A, Gelagoti, M, Drevelegas, A, Diakou, A, et al, 2003: CT and MR imaging findings in cerebral toxocaral disease. AJNR Am. J. Neuroradiol. 244:714-8.

Yong, VW, Power, C, Forsyth, P, Edwards, D R, 2001: Metalloproteinases in biology and pathology of the nervous system. Nat. Rev. Neurosci. 27:502-11.

Zhou, J, Li, M, Jin, WF, Li, XH, Zhang, YY, 2018: Role of NF- $\mathrm{BB}$ on neurons after cerebral ischemia reperfusion. Int. J. Pharmacol. 4:451-9.

\section{Explanation of figures}

Fig. 1: A brain section of T. canis-infected mouse 7 weeks P.I. showed a cut section in T. canis larva (yellow arrow) without inflammatory cell infiltration around it $(\mathrm{H} \& \mathrm{E} \times 400)$.

Fig. 2: Brain sections of negative control and T. canis-infected mice showed immunohistochemical expression of MMP-3 within glial cells (Immunoperoxidase $\times 400$ ). A- Control group showed negative MMP-3 expression, B- Infected group 3 weeks P.I. showed weak increase in 
percentage of MMP-3 stained area, C- Infected group 7 weeks P.I. showed moderate increase in percentage of MMP-3 stained area, DInfected group 15 weeks P.I. showed marked increase in percentage of MMP-3 stained area.

Fig. 3: Brain sections of negative control and T. canis-infected mice showed immunohistochemical expression of MMP-9 within glial cells (Immunoperoxidase $\times 400$ ): A- Control group showed negative MMP-9 expression, B- Infected group 3 weeks P.I. showed weak increase in percentage of MMP-9 stained area, C- Infected group 7 weeks P.I. showed moderate increase in percentage of MMP-9 stained area, DInfected group 15 weeks P.I. showed marked increase in percentage of MMP-9 stained area.
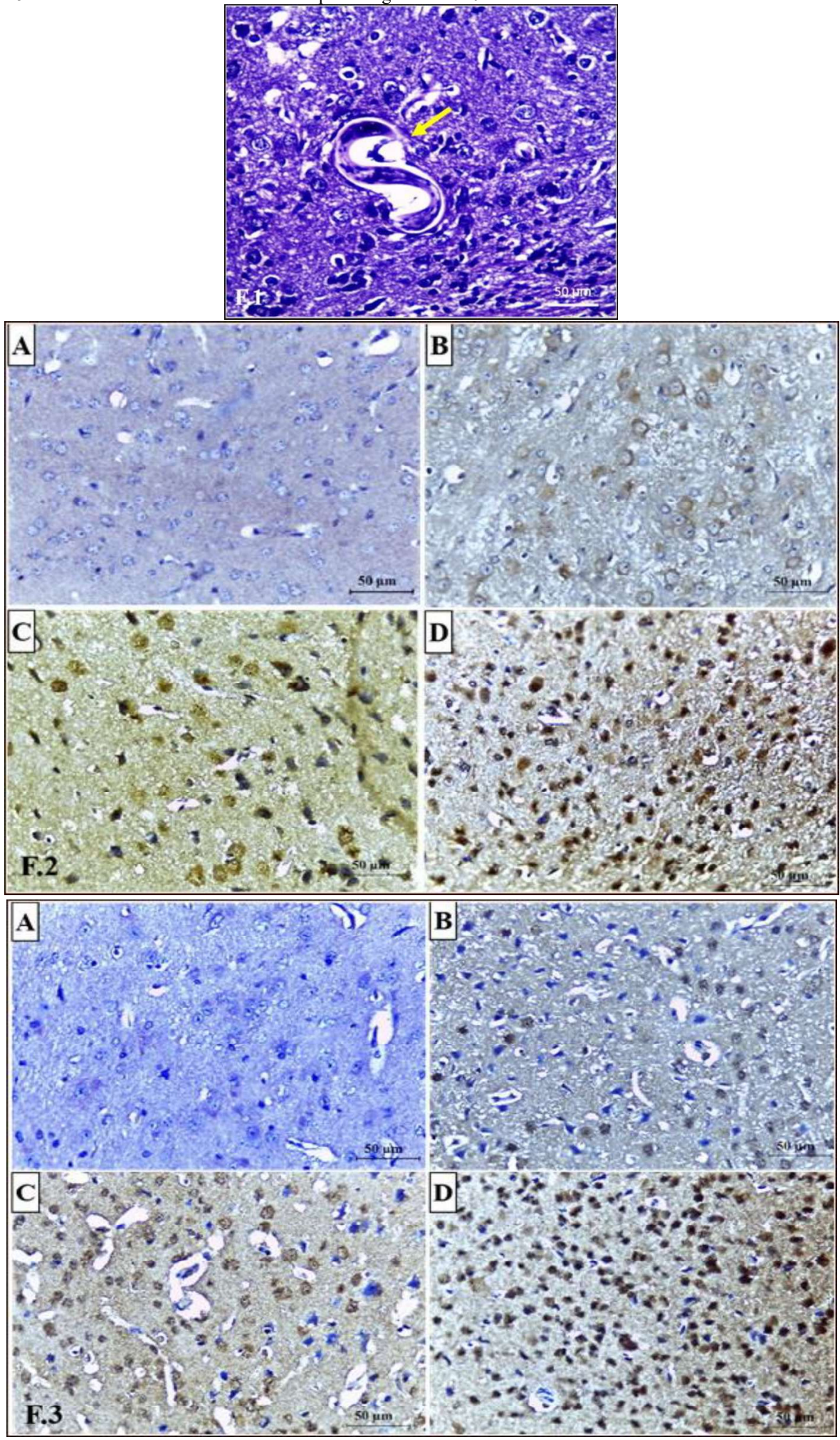